\title{
Prevalência do gênero frente a hipersensibilidade ao níquel em pacientes submetidos
}

\section{a tratamento ortodontico}

\author{
Prevalence of gender against hypersensitivity to nickel in patients undergoing orthodontic \\ treatment
}

Recebido: 11/10/2021 | Revisado: 15/10/2021 | Aceito: 24/10/2021 | Publicado: 31/10/2021

Camila Soares Garcia

Universidade Brasil, Brasil

E-mail: camila.soaressg@outlook.com

Michele Cristina Silva do Vale

Universidade Brasil, Brasil

E-mail: neuromvale@gmail.com

Camila Stefani Santos de Oliveira

Universidade Brasil, Brasil

E-mail: camilastefaniemail@gmail.com

Hellen Gabrielle Soares Lucas

Universidade Brasil, Brasil

E-mail: helengaabisl@gmail.com

Milena de Toledo Alcade

Universidade Brasil, Brasil

E-mail: milena.toledo96@hotmail.com

Antonio Lucio Sant'Ana Neto

Universidade Brasil, Brasil

E-mail: alsantananeto@msn.com

\begin{abstract}
Resumo
Este estudo tem por objetivo revisar sistematicamente o que a literatura apresenta a respeito da prevalência de gênero e hipersensibilidade ao níquel em pacientes submetidos a tratamento ortodôntico com aparelho fixo. Método: Utilizando a metodologia de sistematização da mineração dos dados, com coleta nas bases do PubMed, SciELO e Bireme, a partir das fontes Medline e Lilacs. A busca nos bancos de dados foi realizada com bases em artigos dos últimos vinte anos, com as seguintes palavras-chave: Ortodontia; Aparelhos ortodônticos; Alergia ao níquel; Hipersensibilidade; Hipersensibilidade ao níquel. Conclusão: A literatura sugere que existe relação entre a prevalência de hipersensibilidade ao níquel e o gênero feminino seja por questões de superabundância do íon metálico no organismo, devido o uso de brincos e piercings, ou pela maior procura devido questões estéticas.
\end{abstract}

Palavras-chave: Ortodontia; Aparelhos ortodônticos; Alergia ao níquel; Hípersensibilidade ao níquel.

\begin{abstract}
This study aims to systematically review what the literature presents regarding the prevalence of gender and hypersensitivity to nickel in patients undergoing orthodontic treatment with a fixed appliance. Method: Using the methodology of systematization of data mining, with collection in the databases of PubMed, SciELO and Bireme, from Medline and Lilacs sources. The search in the databases was based on articles from the last twenty years, with the following keywords: Orthodontics; orthodontic appliances; Nickel allergy; Hypersensitivity; Hypersensitivity to nickel. Conclusion: The literature suggests that there is a relationship between the prevalence of hypersensitivity to nickel and the female gender, either because of an overabundance of metallic ions in the body due to the use of earrings and piercings, or because of greater demand due to aesthetic issues.
\end{abstract}

Keywords: Orthodontics; Orthodontic appliances; Nickel allergy; Hypersensitivity to nickel.

\section{Introdução}

Vivemos em uma época que o apelo estético tem grande peso na auto-estima de uma consideravel porção das pessoas, existindo uma infinita busca por um padrão de beleza muitas vezes irreal, ou anti-natural, como visto na procura por dentes extremamente brancos, com formato único, e alinhamento modelo. É possível observar um aumento na procura por correções 
no sorriso, sejam elas dentárias, ou de ordem esquelética. Nesse contexto os aparelhos ortodônticos, podem ser utilizados como uma ferramenta de grande auxilio para obtenção de um resultado mais funcional, e estético. (Couto et al, 2020).

A ortodontia corretiva, tratando-se de aparelhos fixos faz uso da técnica de condicionamento ácido na superfície do esmalte, o que nos permite a fixação de bráquetes de metal no elemento dentário. (Maï-Tam, 2018). Todavia alguns pacientes podem apresentar sensibilidade aos materiais metálicos que fazem parte da composição dos aparelhos ortodônticos, por exemplo, o níquel, sendo grande parte originada pelo sistema imune do paciente, podendo promover lesões a nível celular, e epitelial. (Menezes et al, 2009; Silva et al, 2009).

Uma alternativa para o fator de hipersensibilidade mediante aos metais empregados na confecção dos aparelhos ortodônticos fixos é o emprego de alinhadores ortodônticos transparentes, ou clear aligners. Dentre os benefícios podemos citar: higiene bucal facilitada, maior condição estética, conforto ao paciente, e metal-free. Transformando-se em uma opção de tratamento para pacientes que possuem bruxismo associado pois, além de corrigir más oclusões, o alinhador melhora de forma significativa o desconforto miofacial, e o desgaste oclusal gerado pelos hábitos parafuncionais. (Monguilhot et al, 2017).

\section{Revisão de Literatura}

A demanda por um sorriso mais estético em pacientes adultos tem aumentado a cada dia, levando-os a procura do tratamento ortodôntico corretivo. A Literatura cita que essa procura pelo belo, e estético se firmou em meados dos anos 90 , e perdura cada vez maior até os dias de hoje. Dentre os sistemas de aparelhos ortodônticos mais usados estão: aparelhos fixos, aparelhos móveis, e alinhadores ortodônticos. (Cordeiro, 2020).

Pensando-se em ligas metálicas utilizadas em ortodontia, as reações de hipersensibilidade podem ser observadas a partir de manifestações de ordem local, contudo, podendo evoluir para quadros que afetem o individuo de forma sistêmica por meio de alterações do sistema imune. Dessa forma, é cada vez mais importante o estudo e compreensão a respeito da biocompatibilidade dos materiais ortodônticos, e suas possíveis reações, a fim de proporcionar maior segurança para a saúde do paciente. (Menezes et al, 2009).

O níquel corresponde cerca de $50 \%$ da composição das ligas ortodônticas, seguidas de aço inoxidável, até $8 \%$. A correlação do metal dos aparelhos ortodônticos com a saliva, dentifrícios, e alimentos pode ser uma das causas de corrosão deste material, pois possui relação direta com a alta taxa de liberação deste íon na cavidade bucal. (Zigante et al, 2020).

Reações de hipersensibilidade aos materiais ortodônticos, muitas vezes tem sua origem em uma resposta do sistema imunológico do paciente, que pode tomar proporções exageradas ocasionando lesões celulares, e epiteliais; Enquanto as reações alérgicas conceituam-se como hipersensibilidade especifica do sistema imune, que pode ser desencadeado por uma fonte exógena, ou endógena. (Silva et al, 2009).

Dentre os materiais mais utilizados para composição dos aparelhos ortodônticos estão, o látex, resinas acrílicas, resinas compostas, e as ligas metálicas, como por exemplo o níquel. Os materiais metálicos por si só apresentam características potencialmente tóxicas durante o tratamento ortodôntico, decorrentes da liberação iônica na cavidade bucal, que pode gerar efeitos de hipersensibilidade agudos, ou crônicos a esses pacientes. (Menezes et al, 2009).

Na odontologia, o uso de metais como o níquel, advém da necessidade da trocas das ligas de ouro e metais preciosos na composição de coroas e próteses, conferindo melhorias nos quesitos dureza, expansão e maior resistencia a corrosão. Todavia, o níquel é um composto da classe dos metais que esta presente em nosso dia-a-dia nos alimentos, ligas metálicas, piercings, brincos, jóias e zíperes. Já para fins ortodônticos, o níquel foi utilizado a primeira vez em meados de 1970 , devido suas características de memória de forma, superelasticidade e termo elasticidade. Estudos sugerem que o níquel está associado 
à dermatite alérgica de contato, visto que aproximadamente $28,5 \%$ da população possui alergia a este material, em sua maioria do gênero feminino. (Costa et al, 2003).

A dermatite de contato é um dos problemas mais relevantes causado pela exposição ao níquel seguido por câncer de pulmão, e câncer na mucosa nasal. Essa relação entre a dermatite de contato e a sensibilidade ao níquel está ligada ao fator de exposição do indivíduo que pode ter contato com o níquel na água, solo, alimentos, cigarros, além de adereços metálicos como brincos, e piercings, sendo impossível, não ter contato com o material, visto que ele compõe 3\% da crosta terrestre, e está presente também no ar atmosférico. (Pavesi, 2020). O contato com o níquel em pessoas que possuem hipersensibilidade predispõe a dermatite alérgica de contato que ocorre devido uma resposta imunológica do individuo onde a sintomatologia pode ser leve, ou grave causando exsudato, eritemas, pápulas, descamação, e ardor do local afetado. Essa relação é mais comumente vista em indivíduos do sexo feminino, visto que as reações alérgicas ocorrem proporcionalmente à exposição ao metal. Em mulheres, a incidência de brincos, e piercings é esmagadoramente maior, explicando assim essa implicação. O níquel tem sua relação de hipersensibilidade ligada ao timo, que é um órgão linfático, que se localiza na área superior da caixa torácica, dependente dos linfócitos. Ao perceber a liberação do níquel o timo pode gerar uma reação alérgica de classe IV, (tardia, e mediada pelos linfócitos), que ocorre devido à sensibilização, e continua exposição do paciente ao material que causa a reação, entretanto essa resposta geralmente tem regride, quando o fator causal é retirado do contato com o individuo. (Paiva, 2005).

As ligas dentárias metálicas sofrem um processo de corrosão e oxidação dentro da cavidade bucal devido à presença de saliva e umidade, ocasionando dessa forma a liberação dos íons metálicos que podem levar a hipersensibilidade do indivíduo. (Costa, 2003). Os brackéts, bandas, fios ortodônticos, ligaduras, e tubos dentários usandos em ortodontia têm em sua composição ligas metálicas como por exemplo o níquel, que conferem maior elasticidade, memória de forma, e termo elasticidade; Entretanto a cavidade bucal é um ambiente úmido, o que predispõe a corrosão, que pode levar a degradação desses materiais, causando a liberação desses íons no ambiente oral. A higiene bucal deficiente é fundamental nesse processo, devido o acúmulo de biofilme dental sobre as superfícies dos materiais metálicos. (Fróis, 2018).

A inadequada higienização pode ser responsável tambem por uma alteração na flora bacteriana bucal, permitindo o surgimento de lesões, inflamações, gengivites, e hiperplasia gengival. (Nunes, 2020).

Alguns autores sugerem o uso de testes de contato para verificação de possíveis alergias a liga metálica de níquel. O teste de contato tem por objetivo verificar a existência de reações alérgicas a determinados materiais, assim como elucidar a hipótese de qual material é a causa da resposta alérgica. Para realização adequada do teste, é necessária a aplicação do material na parte superior das costas, ou, região superior dos braços. Para o teste de sensibilidade ao níquel, a literatura sugere o uso de sulfato de níquel na concentração de 5\%. A retirada do material deve ser feita apenas após 48 horas, para primeira leitura, e analisado novamente 72 horas após aplicação do teste para descartar um processo alérgico após contato com o material. (Lazzarini et al, 2013). (Tabela 1)

Tabela 1. Possíveis respostas ao teste de patch, de acordo com Grupo Internacional de Pesquisa em Dermatite de Contato.

\begin{tabular}{|ll||}
\hline \hline Score & Interpretação \\
- & Reação negativa. \\
$?+$ & Reação duvidosa, leve eritema. \\
+ & Fraca, (sem vesículas); eritema, pequena infiltração. \\
++ & Forte, (edematosa, ou vesicular), eritema, infiltração, vesícular. \\
+++ & Extrema, (bolhosa ou ulcerada), normalmente por coalescência das vesículas. \\
IR & Reações irritantes de diferentes tipos. \\
NT & Não testado. \\
\hline
\end{tabular}

Fonte: Lazzarini et al (2017). 
Entretanto, Paiva, 2005, aponta que a confiabilidade do teste cutâneo realizado por dermatologistas de forma isolada não é determinante para estabelecer um diagnóstico, visto que podem ocorrer reações cruzadas, produzindo falso-negativos, ou falso-positivos, corroborando assim a idéia da necessidade de uma avaliação mais elaborada, que estabeleça uma associação precisa entre os sinais clínicos e exames laboratoriais referente à alergia aos metais presentes nos materiais para montagem de aparelhos ortodônticos. (Paiva, 2005).

\section{Metodologia}

Este estudo constitui-se de uma revisão da literatura especializada, realizada entre março e outubro de 2021, no qual se realizou uma consulta a livros e periódicos presentes na Biblioteca da Universidade Brasil - campus Itaquera, acervo do orientador e por artigos científicos selecionados através de busca no banco de dados do portal da instituição com acesso à: Minha biblioteca, CAPES e EBSCO, bem como, consulta em bases de dados de relevância para a produção do conhecimento em saúde: PubMEd, SciELO e Bireme, a partir das fontes Medline e Lilacs. A busca nos bancos de dados foi realizada com bases em artigos dos últimos vinte anos, com as seguintes palavras-chave: Ortodontia; Aparelhos ortodônticos; Alergia ao níquel; Hipersensibilidade ao níquel. (Estrela, 2018; Ludke et al, 2013).

\section{Discussão}

O conceito de biocompatibilidade, toxicidade, hipersensibilidade, e alergia, devem ser estudados e compreendidos pelo Cirurgião Dentista, com intuito de prevenir, ou tratar quaisquer reações adversas que possam acontecer durante o tratamento odontológico. A biocompatibilidade é entendida como a habilidade de um material cumprir as funções para o que foi determinado sem causar processos danosos ao organismo do indivíduo. A biocompatibilidade é atingida quando o material utilizado e os tecidos estão em íntimo contato, todavia, não é observada reação tóxica, alérgica ou irritante. Alguns materiais utilizados no tratamento ortodôntico tem a capacidade de alterar a atividade biologia do individuo podendo causar reações não desejadas em nível local, ou sistêmico, o que reforça a idéia da importância da compreensão das propriedades dos materiais disponíveis no mercado. (Jorge et al, 2004; Menezes et al, 2009; Westphalen, 2006).

Não obstante que a interação entre os tecidos do individuo, e os materiais metálicos possam acontecer de variadas formas, o fator principal a respeito da hipersensibilidade é como irá ocorrer a liberação dos elementos iônicos da liga metálica no interior da cavidade bucal. Visto que essa liberação pode superabundar o organismo desses íons causando reações adversas tais como irritação, hipersensibilidade e alergia. (Menezes et al, 2009; Pantuzo et al, 2004).

Alguns estudos descrevem a relação entre a hipersensibilidade em pacientes submetidos a tratamentos ortodônticos, e a liberação iônica de materiais metálicos como o níquel. Esse material constitui de $8 \%$ a $20 \%$ da composição de bráquetes ortodônticos, o que somado ao tempo de tratamento pode ser entendido como fator etiológico para o surgimento de reações adversas. (Torrel, 2017).

Torrel, 2017 investigou a prevalência de hipersensibilidade ao níquel em 87 crianças de 5-12 anos da cidade de Santa Maria, (Rio Grande do Sul). Os indivíduos foram testados com teste cutâneo de sensibilidade ao níquel 'patch test'. Os resultados sugerem uma maior sensibilização no sexo feminino 67,6\%, em relação ao sexo masculino, $32,4 \%$.

Resultado esse que corrobora com os achados de Costa, 2003, que após avaliar por meio de patch test, 65 pacientes com idade de oito (8), a tinta e cinco (35), anos, de ambos o gêneros verificou uma maior prevalência de 9,23\% de pacientes reativos ao níquel, sendo que $17,14 \%$ eram do gênero feminino, estabelecendo assim uma associação da hipersensibilidade ao níquel com o gênero, Costa ainda sugere que essa associação pode estar relacionada à maior exposição das mulheres a 
materiais que contêm níquel, visto que mulheres têm mais furos de brincos, e piercings, aumentado sobremaneira a exposição do organismo ao níquel, dando inicio ao processo de sensibilização. (Costa et al, 2003).

Paiva, (2005), pontua a predominância de hipersensibilidade do gênero feminino como uma questão de maior demanda, e procura. Em amostra com 22 pacientes, verificou-se uma predominância de 73\% do gênero feminino, entretanto a autora sugere que pacientes do gênero feminino procuram o tratamento ortodôntico com maior frequência que os pacientes do gênero masculino por questões de ordem estética. Ainda no mesmo estudo é reforçada a ideia que quanto maior o contato com o material, maior a propensão de desenvolver hipersensibilidade, visto que dentre os participantes, dois, (2) pacientes não faziam uso de objetos metálicos, o que corresponde a 9,09\% da amostra. Três (3), pacientes iniciaram o uso de metal após o inicio do tratamento, e um total de 77,27\% relatou já fazer uso de objetos metálicos antes do inicio do tratamento ortodôntico, caracterizando um total de $77,27 \%$ da amostra já sensibilizada ao contato com níquel, aumentado a chance de hipersensibilidade após a montagem do aparelho ortodôntico. (Paiva, 2005).

Garcia e colaboradores, 2003, avaliaram a hipersensibilidade aos elementos metálicos dos bráquetes ortodônticos, em uma amostra com 58 indivíduos, de 11 a 30 anos de idade, sendo 48,3\% do gênero feminino, e 51,7\% do gênero masculino. Este trabalho analisou a incidência de hipersensibilidade provocada pelo aparelho ortodôntico, por meio de testes de sensibilidade cutânea (patch test), e protocolos clínicos periodontais. A respeito da prevalência de gênero, em relação à sensibilidade ao níquel verificou-se que no grupo feminino, aproximadamente $50 \%$ de casos a reação alérgica ao níquel foi testada positiva. Todavia no grupo masculino, este percentual foi de 6,7\% corroborando para uma diferença significativa entre os gêneros. Esses valores são justificados pelo uso prévio de brincos em todas as mulheres constituintes da amostra, confirmando a hipótese de que mulheres apresentam maior percentual de sensibilidade ao níquel devido maior exposição a esse metal. (Garcia, 2003).

\section{Conclusão}

Concluiu-se que a hipersensibilidade ao níquel tem intima relação com a exposição ao metal, seja por uso de objetos metálicos, presença em alimentos, solo, ou como parte constituinte do material dos aparelhos ortodônticos.

A literatura ainda sugere que indivíduos do sexo feminino tem maior predisposição à hipersensibilidade ao níquel, devido à sensibilização prévia ao níquel mediante o uso de objetos metálicos com brincos, piercings, cintos e acessórios, causando uma superabundância desse elemento que em indivíduos sensíveis pode levar a alergias, sensibilidade, e eritemas. É necessária uma gama maior de estudos para estabelecer a relação entre gêneros e a maior prevalência de hipersensibilidade ao níquel, por uma ótica fisiológica, e celular, visto que a literatura já aponta uma relação comportamental, e social para a prevalência de maior sensibilidade apresentada no gênero feminino.

\section{Referências}

Costa, M. T., Dias, F., \& Lenza, M. A. (2003). Hipersensibilidade ao níquel em paciente sob terapia ortodôntica. Rev. bras. alerg. Imunopatol, $26(1)$, 02-11.

Couto, B. L. B., \& Abreu, L. G. (2020). Comparação entre alinhadores ortodônticos e aparelhos ortodônticos fixos convencionais: uma revisão sistemática e meta-análise. Arquivos em Odontologia, 56.

Cordeiro, J. V. C. (2020). Estudo comparativo entre Aparelhos Ortodônticos Fixos e Alinhadores Removíveis: Revisão de Literatura.

Estrela, C. (2018). Metodologia Científica: Ciência, Ensino, Pesquisa. Editora Artes Médicas.

Frois, A. M. J. (2018). Funcionalização de Ligas Ortodônticas com Revestimentos DLC (Doctoral dissertation, Universidade de Coimbra).

Jorge, J. H., Giampaolo, E. T., \& Pavarina, A. C. (2013). Citotoxicidade dos materiais dentários. revisão de literatura. Revista de Odontologia da UNESP, 33(2), 65-68.

Lazzarini, R., Duarte, I., \& Ferreira, A. L. (2013). Patch tests. Anais brasileiros de dermatologia, 88, 879-888. 
Ludke, M \& Andre, M. E. D. A. (2013). Pesquisas em educação: uma abordagem qualitativa. E. P. U.

Maï-Tam, K. (2018). Tratamento ortodôntico com brackets ou alinhadores: estudo comparativo (Doctoral dissertation).

Menezes, L. M. D., Freitas, M. P. M., \& Gonçalves, T. S. (2009). Biocompatibilidade dos materiais em Ortodontia: mito ou realidade? Revista Dental Press de Ortodontia e Ortopedia Facial, 14, 144-157.

Monguilhott, L. M. J., \& Zanardi, G. (2017). Tratamento ortodôntico com o sistema Invisalign: a utilização de alta tecnologia na realização de movimentos dentários. Rev Clín Ortod Dental Press 2017; $16(1): 56,73$.

Nunes, A. F., Fogaça, C. L., Grande, R. S., Kayser, E. G., \& de Souza, B. C. (2020). Comparação de técnicas ortodônticas e uma sugestão de tratamento para o paciente atleta. Disciplinarum Scientia| Saúde, 21(1), 267-283.

De Paiva, V. C. X. (2005). Hipersensibilidade ao níquel presente no aparelho ortodôntico fixo metálico. Avaliação Clínica, Periodontal, Histopatológica E Imunoistoquímica (Doctoral dissertation, Dissertação (Mestrado em Ortodontia). Minas Gerais: Pontifícia Universidade Católica de Minas Gerais).

Pantuzo, M. C. G., Zenóbio, E. G., Marigo, H. D. A., \& Zenóbio, M. A. F. (2007). Hypersensitivity to conventional and to nickel-free orthodontic brackets. Brazilian oral research, 21, 298-302.

Pavesi, T. (2020). Importância toxicológica da exposição a níquel, cobalto e cromo: a dermatite de contato a metais e a susceptibilidade genética a cromo (Doctoral dissertation).

Silva, B. G. V., Vêncio, E. F., DE Souza, J. B., Lenza, M. A., \& Azevedo, M. N. (2019). Efeitos biológicos adversos causados pelo níquel no organismo: Uma revisão narrativa. Anais da Jornada Odontológica de Anápolis-JOA.

Torrel, B. (2017). Estudo da prevalência da alergia ao níquel através de teste cutâneo em crianças de 5-12 anos.

Westephalen, G. H. (2007). Avaliação de hipersensibilidade a metais e toxicidade genética associadas ao uso de aparelhos ordotônticos fixos.

Zigante, M., Mlinaric, M. R., Kastelan, M., Perkovic, V., Zrinski, M. T., \& Spalj, S. (2020). Symptoms of titanium and nickel allergic sensitization in orthodontic treatment. Progress in Orthodontics, 21(1), 1-7. 